\begin{tabular}{|c|c|c|}
\hline $\begin{array}{l}\text { PKS } \\
\text { PUBLIC } \\
\text { KNDOLEDGE } \\
\text { PROJECT }\end{array}$ & $\begin{array}{l}\text { REVISTA DE GEOGRAFIA } \\
\text { (RECIFE) } \\
\text { http://www.revista.ufpe.br/revistageografia }\end{array}$ & $\begin{array}{l}\text { OJS } \\
\text { OPEN } \\
\text { JOLNAL } \\
\text { SYSTEMNS }\end{array}$ \\
\hline
\end{tabular}

\title{
ABORDAGEM GEOGRÁFICA E APLICAÇÃO DOS CONCEITOS DE GEOFORMA E GEOMORFOSSÍTIO
}

\author{
Telma Mendes da Silvali ${ }^{1}$ Eluan Alan Lemos Pocidônioº
}

${ }^{1}$ Professora Associada II do Departamento de Geografia da UFRJ.E-mail: telmendes@globo.com

${ }^{2}$ Doutorando do Programa de Pós-Graduação em Geografia - PPGG/IGEO-UFRJ. E-mail: eluanlemos@yahoo.com.br

Artigo recebido em 03/11/2017 e aceito em 08/01/2018.

\begin{abstract}
RESUMO
Este trabalho teve por motivação principal trazer para debate a utilização de conceitos-chave geográficos na leitura da paisagem, procurando enfatizar a aplicação dos termos geoformas e geomorfossítios e sua utilização em questões de cunho ambiental, subsidiando-se desta abordagem para estudos que almejem a conservação e valorização dos recursos naturais. Procuramos, deste modo, resgatar a importância desta discussão nas raízes da ciência geográfica visando um melhor posicionamento das pesquisas contemporâneas que envolvem esta temática, demonstrando o quão geográfico está atrelada esta abordagem teórico-conceitual no estudo das paisagens. Exemplificamos, ainda, dentro desta proposta metodológica a vertente que procura valorizar o patrimônio geomorfológico de uma dada área, ressaltando-se que este é passível de apreensão em distintos níveis escalares de ocorrência, por meio do reconhecimento e da definição de geoformas e geomorfossítios em escala local até a escala regional.
\end{abstract}

Palavras-chave: Escalas de análise, Paisagem, Geoforma, Geomorfossítio.

\section{GEOGRAPHICAL APPROACH AND APPLICATION OF GEOFORM AND GEOMORPHOSITE CONCEPTS}

\begin{abstract}
This work has as its main motivation to bring the use of geographical key concepts in reading the landscape to debate, seeking to emphasize the application of the terms geoforms and geomorphosites and their use in environmental matters, subsidizing this approach for studies that aim at conservation and appreciation of natural resources. This way, we seek to recover the importance of this discussion at the roots of the geographic science, aiming at a better positioning of the contemporary researches that involve this theme, demonstrating how geographic this theoretical-conceptual approach is in the study of landscapes. We also exemplify, within this methodological proposal, the aspect that seeks to value the geomorphological heritage of a given area, highlighting that it is subjected to different levels of apprehension, by means of the recognition and definition of geoforms and geomorphostites from local scale to a regional scale.
\end{abstract}

Keywords: Analysis scales, Landscape, Geoform, Geomorphosites. 


\section{INTRODUÇÃO}

Neste artigo, procuraremos trazer para debate a discussão dos termos "geoforma" e "geomorfossítio" dentro de uma abordagem geográfica e, desta forma, trabalhar com uma metodologia teórico-metodológica, visando à leitura da paisagem de diferentes lugares da superfície terrestre.

Estas terminologias, que vêm tendo uma considerável aceitação e utilização nas últimas décadas, principalmente, devido à importância de questões mais específicas de cunho ambiental, subsidiam uma nova abordagem à questão da conservação e valorização dos recursos naturais e, ao mesmo tempo, procuram alertar para o interesse dos recursos naturais abióticos (também conhecido por geodiversidade). Tais terminologias possuem relação direta com o setor econômico do turismo, por buscar novas formas de promovê-lo e por levar em consideração aspectos da geodiversidade, em especial a paisagem, como alternativa ao turismo tradicional muitas vezes calcado no preceito "sol e mar".

A utilização de atributos abióticos da Terra vem ganhando proporções significativas no que tange os estudos que tratam do reconhecimento científico, na definição de localidades que possuam atrativos para a valorização neste setor da economia. Assim, termos que outrora eram utilizados, quase que exclusivamente pela Geografia, ou mais especificamente, na pesquisa geomorfológica, tomaram vulto, transcendendo para outras áreas tais como Geologia, Economia, Arquitetura, Engenharia, Ecologia e Turismo. Deste modo, pretendemos resgatar a importância desta discussão nas raízes da ciência geográfica para um melhor posicionamento das pesquisas que envolvem este tema em estudos geógraficos, pois, na atualidade, muitas áreas vêm trabalhando nesta vertente, mas sem terem uma real dimensão do quão geográfico define tais terminologias.

Por conseguinte, procuraremos fazer uma discussão de conceitos-chave da ciência geográfica, considerando elementos embrionários para a construção de termos como "geoforma" e "geomorfossítio", respaldando-os em seu caráter científico e fortalecendo-os mediante o uso e à aplicabilidade em diferentes setores da economia.

\section{Conceitos geográficos como critérios de análise espacial}

Iniciamos a discussão com a concepção do termo paisagem, que se refere a um dos conceitos-base da discussão geográfica e, para tanto, relembramos que desde a Antiguidade este termo sempre esteve muito presente nas obras de artes em geral, sendo incorporado como conceito acadêmico somente na Modernidade (VERDUM e MAZZINI, 2009, p.9). Em 
Geografia, o conceito de paisagem é visto como um conjunto de formas naturais e culturais, associadas em uma dada área, e que pode ser analisado morfologicamente, vendo-se tanto a integração das formas entre si, quanto o caráter orgânico ou "quase orgânico" das mesmas, considerando-se ainda que o tempo seria uma variável fundamental de análise (CORRÊA e ROSENDAHL, 1998, p.9). Ou seja, a paisagem resulta da interação, ao longo do tempo, entre cultura e natureza - esta que também possui aspectos específicos em sua evolução.

"Os geógrafos analisam os elementos que compõem a paisagem, em função de sua forma e magnitude, e propõem uma classificação das paisagens. Assim sendo, é de fundamental importância, nesse tipo de procedimento, que a paisagem seja considerada como o conjunto dos elementos da natureza que podem ser observados a partir de um ponto de referência. Além disso, na leitura da paisagem, é possível definir as formas resultantes da associação do ser humano com os demais elementos da natureza. As dificuldades encontradas pelos geógrafos para conceberem a paisagem dessa maneira são relacionadas à definição das heterogeneidades e das homogeneidades em relação à escala espacial, assim como à complexidade das formas da superfície terrestre. Nesse sentido, é fundamental considerar a natureza como uma mudança contínua de formas e de movimentos cíclicos, periódicos e em intervalos desiguais, que conduzem a uma constante renovação de formas e funcionamentos" (VERDUM e MAZZINI, 2009, p.10).

A apropriação intelectual/cultural do termo paisagem, dentro de um contexto ecosócio-sistêmico, segundo a concepção de Cauquelin (2007; p.12) está centrado na ideia de que “a noção de paisagem e sua realidade percebida são justamente uma invenção, um objeto cultural patenteado, cuja função própria é reassegurar permanentemente os quadros da percepção do tempo e do espaço. E, na atualidade, é fortemente evocada e preside todas as tentativas de "representar" o planeta como eco-sócio-sistema".

Para Jakob (2008; p.17) a complexidade que envolve "o discurso da paisagem assume, por definição, as formas mais variadas. Sendo a paisagem dita e escrita de maneiras e contextos diferentes". Deste modo, "deveríamos explorar muito mais a fundo (...) como os seres humanos criam lugares no espaço e os embuem de significado; como as sociedades contemporâneas (re)descobrem e (re)inventam lugares e paisagens" (NOGUÉ, 2009, p.123).

Dentro deste caminho analítico, outro termo geográfico atrelado à discussão conceitual abordada corresponde ao 'lugar', que foi definido por Santos (1996, p.258) como o quadro de uma referência pragmática ao mundo, do qual the vem solicitações e ordens precisas de ações condicionadas, e, nas quais, tais ações se referem também aos fenomênos de ordem natural que alteram os aspectos da paisagem. Sobre este conceito Costa e Rocha (2010) assinalam que, na concepção da Geografia Tradicional, o lugar seria definido de acordo com 
as características naturais e culturais próprias de uma determinada área, e estaria ligado à noção de localização e à individualidade das parcelas do espaço. Já na Geografia Crítica, passa-se a valorizar mais questões políticas e econômicas. Na Geografia Humanística tem-se um peso incomparável na relevância que o termo lugar adquiriu entre os geógrafos. Dessa forma, o lugar seria o espaço do singular, estando presentes elementos históricos, culturais e a identidade local que revelaria especificidades locais. Logo, a conceituação de "geoforma" e "geomorfossítio", que serão tratados no próximo item, estaria diretamente relacionada ao conceito geográfico de lugar, sendo caracterizado, reconhecido e diferenciado a partir de identidades do local, ou seja, de suas especificidades.

Ressaltamos que, Paul Vidal de La Blache (1845-1918) destacou em toda sua obra que para se entender a ação humana junto à natureza a interdisciplinaridade era essencial e, assim, sua análise espacial parecia estar à frente de seu tempo, onde esta deveria dialogar, a todo instante, com outras ciências como Geologia, Sociologia e História na busca de particularidades inerentes aos lugares (HAESBAERT et al. 2012). La Blache, portanto, se contrapunha à ideia de leis gerais para explicar todos os fenômenos em todos os lugares, ressaltando que para a interpretação das paisagens existem causas passadas e presentes atuantes conjuntamente em diferentes escalas e que se misturam e dão significado local, isto é, reconhecia a importância da diferenciação como processo geográfico.

No rastro das ideias do alemão Alfred Hettner, o americano Richard Hartshorne (1899-1992) acrescentava que a Geografia é "uma ciência que interpreta as realidades da diferenciação de áreas do mundo, tais como elas são encontradas, não somente em termos das diferenças de certos elementos de lugar para lugar, mas também em termos da combinação total dos fenômenos em cada lugar, diferente daquelas que se verificam em cada um dos outros lugares (HARTSHORNE, 1939, p.462) e, desta forma, procurando interpretar o caráter variável da superfície terrestre, de lugar a lugar, assim como a atividade do ser humano. Para este estudo científico deve incluir tanto o que se sabe, quanto o que pode ser inferido, quer dos fenômenos, quer das relações de processos e associações de fenômenos, definindo que os lugares são singulares.

Sabe-se que a diferença entre espaço e lugar, e mesmo entre lugar e outros conceitos espaciais, deriva de matrizes interpretativas bastante complexas na evolução do pensameno geográfico, que transitam desde teorizações de inspiração marxista àquelas de cunho mais humanístico, como sugere Hubbard (2005). Contudo, é possível recuperar supostos comuns a tais matrizes, como procede Tim Cresswell ao sublinhar, apoiado em Fred Lukerman, que a "geografia é o conhecimento do mundo como ele existe nos lugares" (LUKERMAN, 1964 in 
CRESSWELL, 2010: 18). O mesmo Cresswell nos adverte:

"Mas o lugar é também um modo de ver, conhecer e compreender o mundo. Quando olhamos para o mundo como um mundo de lugares vemos coisas diferentes. Vemos laços e conexões entre gente e lugar. Vemos mundos de significados e experiência (CRESSWELL, 2010:11).

Souza (2013) ressalta em seu livro "Os conceitos fundamentais da pesquisa sócioespacial" que o lugar, comparado com outros conceitos, como o de território, teria mais explicitamente uma dimensão cultural-simbólica, envolvendo identidade, intersubjetividade e trocas simbólicas (p.115). O autor remete-se ao colocado por Yi-Fu Tuan, que define lugar como uma realidade correspondente ao laço afetivo entre as pessoas e o ambiente circundante, reconhecendo-se, em decorrência, o que a filosofia de Gaston Bachelard havia conceituda como topofilia. Tuan (1983: 151) sugere ainda que o "espaço se transforma em lugar, à medida em que adquire definição e significado". Nessa linha interpretativa, depreende-se que o conceito de lugar se refere ao espaço percebido e vivido; àquele segmento do espaço que se refere à realidade experienciada pelos sujeitos.

A contribuição de Tuan não para por aqui, pois segue promovendo uma série de debates e raciocínios atrelados ao conceito de lugar. Bastaria mencionar a inter-relação que ele estabelece entre lar e lugar, demonstrando que a noção de lugar é, antes de tudo, aquela que nos traz a sensação de acolhimento, como o "nosso lar" (TUAN, 2005). Também, o autor nos recorda que o ambiente, seja em sua dimensão natural - geológico-geomorfológica, ou construída - arquitetônica, deve ser apreendido pelos sujeitos por meio de todos os sentidos, ainda que a visão, na maioria dos casos, seja priorizada. Ele afirma: "Podemos inferir a natureza do mundo perceptivo, em parte, por aquilo que existe para se perceber" (TUAN, 1984: 130). Essa afirmação nos remete à noção de lugar como espaço da vida, um existente complexo que precisamos decifrar pelos sentidos.

Dentro deste raciocínio, Oslender (2004) sintetiza três aspectos principais da discussão geográfica em torno da ideia de lugar: localização, local e sentido de lugar. A localização se refere à área geográfica físico-material que é afetada por processos econômicos e políticos. $\mathrm{O}$ local refere-se ao quadro espacial formal e/ou informal no qual interações e relações cotidianas são constituídas, e o sentido do lugar estaria relacionado ao modo de como a experiência e a imaginação do ser humano se reflete na apreensão subjetiva, derivadas do viver em um lugar particular.

Como termos importantes na análise geográfica, Souza (2013) introduz a lugarização/deslugarização, relugarização e lugaridade que acaba por ser bastante importante 
como embasamento da análise espacial aqui introduzida e fundamental na construção teóricometodológica da abordagem contemporânea de "geoforma" e "geomorfossítio". A lugarização se ateria à motivação de tornar familiar e dotar de significado porções do espaço com as quais se tem interação. A relugarização passaria pela atribuição de novos significados aos lugares, que pode ser feito por meio de representações da paisagem, novas adjetivações e descrições, de revisão da história, ou seja, reescrevendo a narrativa da história do lugar, relendo o passado e influenciando o futuro (SOUZA, 2013, p.125). Este autor também remete a questão da escala de abordagem do lugar, introduzindo que existiriam diferentes "níveis de lugaridade", desde a escala local, que seria a mais compreenssível, até a escala regional. Ressalta, ainda, que nos dias atuais, o que define é a vivência, sem obedecer a uma hierarquia escalar rígida (SOUZA, 2013, p.127). Além disso, os níveis de lugaridade se alteram com o tempo e as mudanças de vida, que fazem com que o mesmo espaço seja visto de modos distintos, de acordo com a posição de classe, gênero etc. (SOUZA, 2013, p.127), pois estas características fazem com que haja diferentes formas de se relacionar com os lugares, descrevê-los, imaginálos, senti-los e reinventá-los (SOUZA, 2013, p.134).

Trazemos ainda para o debate, especificamente no que tange aos fenômenos da natureza, os preceitos apresentados por Cavalcanti (2011), quando este se refere à especificidade dos lugares, caracterizada pelas distintas relações culturais e formações socioespaciais, bem como pelos distintos processos geológico-geomorfológicos, que atuaram e atuam no mecanismo evolutivo da paisagem, dando características únicas aos lugares e fazendo com que muitos deles sejam exemplares da superfície terrestre, considerados como patrimônio natural do Planeta. Nesse debate, os conceitos de lugar e paisagem parecem formar uma interdigitação inseparável.

Ainda é importante destacar, que há distintas escalas de análise dos mecanismos evolutivos de diferentes lugares que compõem uma paisagem. Para uma análise na escala temporal, deve-se ter em mente dois tempos distintos: tempo dos fatos geológicos que deram origem aos aspectos observados pelo relevo e o tempo dos fatos históricos, onde as atividades humanas exerceram e exercem papel fundamental no mecanismo evolutivo e, por consequência, nas transformações locais. Desta forma, “... diferentes formas de relevo, em diferentes escalas, são formadas a partir de uma combinação ou ação isolada de diversos fatores associados à atividade tectônica, erosão, antropismo e ciclos climáticos..." (MANOSO et al., 2010).

A realização de um levantamento criterioso dos locais de interesse estético e patrimonial, assim como investigações que procurem reunir elementos para uma reflexão 
sobre paisagens futuras, acabam dando uma ideia da dimensão escalar de novos elementos, que poderão ser inseridos em sua funcionalidade e que, portanto, estarão diretamente associadas a medidas e cuidados a serem tomados, quando de vindouras transformações (VERDUM e MAZZINI, 2009, p.14). Pelo exposto, deduzimos que lugares e paisagens entrecruzam-se nesse levantamento, inscrevendo geoformas e geomorfossítios em sua escala.

Como forma de contextualizar esta discussão trazemos para debate a proposta de Gomes e Ribeiro (2013) sobre o valor da relação existente entre uso de imagens e as Geociências. Para estes autores a expressão física pela qual a imagem toma forma visual está diretamente associada ao conteúdo histórico e evolutivo de uma dada localidade, quer sejam estes derivados de processos de natureza físico-ambiental ou sócio-econômicos e, portanto, estariam diretamente relacionados à visibilidade de diferente geoforma ou geomorfossítio. Gomes (2013) ressalta ainda sobre a importância de se aprender e compreender a disposição espacial por meio de imagens, ou seja, sobre aquilo que se é espontaneamente observado pelo olhar. O que vem ao encontro do significado do uso da terminologia de "geoforma" e "geomorfossítio".

A figura 1, intitulada "O Lazareto" de Henry Chamberlain (1822), pode nos servir como um clássico exemplo da utilização da importância e do significado da imagem de paisagens para ilustrar as características físico-ambientais de um dado lugar e, neste caso, especificamente do entorno da Baía de Guanabara. Nesta imagem, podem-se observar não só as feições morfológicas da baixada da Guanabara como feições serranas ao fundo, além de se observarem as referências de cunho estratégico de defesa da própria conformação do contorno litorâneo deste setor do Rio de Janeiro, além do aspecto social onde escravos trabalham e os senhores apreciam o belo cenário natural da Baía de Guanabara. Dentro das concepções contemporâneas aqui em debate, esta seria uma paisagem de conteúdo geológicogeomorfológico ímpar e que serve para exemplificar a abordagem dos conceitos de geoforma e geomorfossítio. A Serra do Mar ao fundo desta ilustração, as praias (em forma de enseada) e ilhas presentes na Baía de Guanabara seriam, em um primeiro momento, geoformas de diferentes escalas espaciais de ocorrência e que poderiam ser classificadas como geomorfossítios, após serem avaliados e atribuído um valor, dado a partir de aspectos que o definam como locais de interesse geomorfológico. 


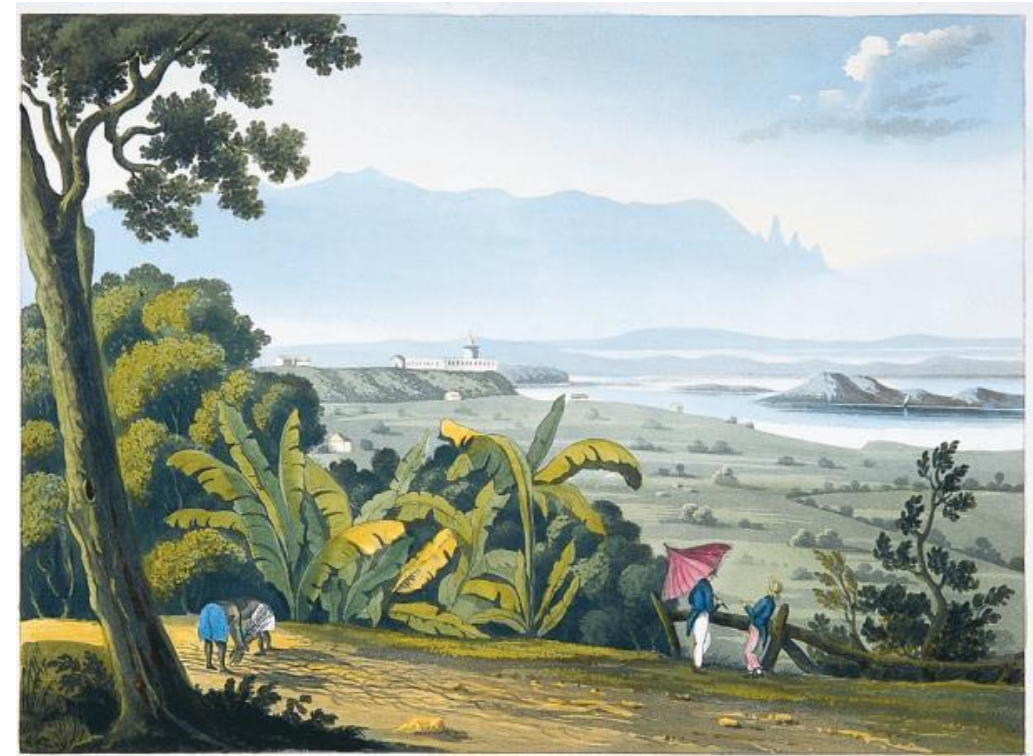

Figura 1. 'O Lazareto' de Henry Chamberlain (1822) - Gravura do acervo da Pinacoteca do Estado de São Paulo, Brasil. Coleção Brasiliana - Fundação Estudar. (Cedida ao uso aos autores em 12.2.2014).

\section{Geoforma e Geomorfossítio como abordagem para a leitura da paisagem}

Dando prosseguimento à discussão, entraremos especificamente na proposta de realizar a leitura de uma paisagem a partir dos conceitos de "Geoforma" e "Geomorfossítio", haja vista que “... dentro do patrimônio natural o geomorfológico é o que priveligia a paisagem” (RODRIGUES et al., 2009).

O termo "geoforma" se refere a um corpo tridimensional com forma (geometria, declividade, altitude...), tamanho e volume específicos. De maneira geral, vem sendo um termo utilizado pela Geografia e, mais especificamente, pela Geomorfologia, como categoria de análise para se reconhecer e identificar feições do relevo e seus aspectos derivados, como topografia, drenagem, textura dentre outros critérios, para a diferenciação e investigação de processos evolutivos de distintas localidades da superfície terrestre.

Manoso et al. (2010; p.2) ressaltam que o termo geoforma designa toda e qualquer forma da superfície terrestre, resultante de processos geológico-geomorfológicos que seja dotado de 'valores' intrínsecos, ou seja, valores de referência que possam vir a serem utilizados para avaliação e justificando que uma dada localidade merece conservação. Estes valores podem, portanto, serem avaliados, tanto pela forma do relevo em si, mas também pelo valor cultural, estético, funcional, educativo e/ou turístico local (BRILHA 2005; 2016). Este pesquisador português é um dos grandes precursores da defesa desta tese, ressaltando que o ato de valorizar e proteger geoformas justifica-se porque lhe é atribuído valor.

"Principalmente sob a ótica científica, é importante conhecer e avaliar as 
geoformas, de modo que aquelas mais importantes cientificamente, ou de elevado valor cênico, estão para o patrimônio histórico-geológico e geomorfológico da Terra, assim como os exemplares únicos de alguns biomas estão para os patrimônios biológicos do planeta" (MANOSO et al. 2010, p.2).

Desta forma, este conceito assume mais evidência nas duas últimas décadas pela comunidade científica internacional, tendo em vista a preocupação ambiental com a biodiversidade e, por extensão à geodiversidade do Planeta. Assim, o conceito (re)surge nas ciências ambientais como forma de sintetizar caracterísicas específicas e, muitas vezes, excêntricas de uma dada localidade geográfica, o que pode elevá-la a "Patrimônio Geomorfológico". Para esclarecimento desta expressão podemos encontrar em trabalhos de Pereira et al. (2004) e Pereira et al. (2006), a consideração de que "Patrimônio Geomorfológico" corresponde a um conjunto de feições do relevo de interesse científico e, neste, as geoformas, bem como os processos que as geraram adquirem valor, principalmente, no que tange à importância particular para a reconstrução e explicação da história da Terra, de suas características climáticas locais e da vida que a suporta. Vale salientar que Pereira (2006, p.333) descreve que "O património geomorfológico é uma das categorias do património geológico, tal como o património paleontológico ou o património mineralógico. Os locais de interesse geomorfológico são geossítios cuja interface com os restantes elementos naturais e culturais do ambiente é reconhecida".

O desconhecimento das componentes biofísicas do sistema ambiental e de suas interações leva à violação das orientações da política ambiental formuladas que, dentre outras considerações, mostra a imprudência e a atitude de desrespeito pela natureza, alteram sua dinâmica evolutiva e os próprios ciclos de regeneração e renovação (PEREIRA, 1995). Nesta linha de pensamento, esta autora propõe uma definição de patrimônio geomorfológico, como sendo:

“... o conjunto de formas de relevo, solos e depósitos correlativos, que pelas suas características genéticas e de conservação, pela sua raridade e/ou originalidade, pelo seu grau de vulnerabilidade, ou ainda, pela maneira como se combinam espacialmente (a geometria das formas de relevo), evidenciam claro valor científico, merecendo ser preservadas" (PEREIRA, 1995, p.12).

O patrimônio geomorfológico, como denominam Figueiró et al. (2013) pode variar desde uma pequena área, envolvendo, e.g., um único elemento geomorfológico, até uma grande área, cuja ocorrência contínua de um ou mais elementos geomorfológicos justifique a sua identificação como um único geossítio.

Cunha e Vieira (2004) e Vieira e Cunha (2004) chamam atenção para a importância da escala em que se pode observar o patrimônio geomorfológico, distinguindo: escala local, 
dimensão da ordem de alguns metros quadrados a alguns milhares de metros quadrados e apenas um elemento geomorfológico com valor patrimonial; escala intermédia, dimensão da ordem de alguns milhares de metros quadrados até alguns quilômetros quadrados, em que se conjugam vários elementos geomorfológicos, formas e depósitos, articulados entre si; escala da paisagem, de dimensão quilométrica ou da ordem da dezenas de quilômetros, em que os elementos geomorfológicos de base são integrados e, sobretudo, valorizados pelos elementos bióticos, notadamente a vegetação, além dos elementos culturais.

Dessa maneira, a avaliação de geoformas subsidiará a definição de locais que possam ser considerados como patrimônio geomorfológico, sendo assim considerados pelo conjunto de locais de interesse e que adquiram valor derivado do interesse científico e da percepção humana, ou seja, das categorias de análise do olhar e da visibilidade dos aspectos e fenômenos envolvidos na herança local (GOMES, 2013). A partir desta definição, se está assim contribuindo para a manutenção das paisagens mais significativas e dos indicadores da sua evolução (PEREIRA, 1995, p. 23).

Cabe ressaltar, que “... é importante que o processo de avaliação se revista da maior objetividade possível, desde a formulação dos seus objetivos até à definição da metodologia de avaliação a adotar. Por outro lado, o conhecimento geomorfológico da área de estudo é fundamental para uma avaliação adequada, devendo ser conduzida por especialistas da área da geomorfologia, se possível em colaboração entre si, ou mesmo com profissionais de outras disciplinas" (ROCHA 2016; p. 28).

Existem na literatura várias propostas metodológicas para a identificação, catalogação, avaliação e a atribuição de valores de locais de interesse geomorfológico, e de fomentar seu conhecimento, valorização e proteção, tais como: Panizza (2001); Reynard e Panizza (2005); Pereira (2006); Reynard et al. (2009) e Pelfini e Bollati (2014). Entre os autores mais bem conceituados e aceitos, se encontra Pereira et al. (2007; p. 236) onde reconhecem que a “... avaliação do patrimônio geomorfológico envolve não apenas o reconhecimento das geoformas a considerar como locais de interesse geomorfológico, mas também a sua comparação, em termos de importância. Trata-se de um procedimento fundamental para a constituição de inventários com suporte científico e para a definição de estratégias de gestão do patrimônio natural". Esta metodologia de avaliação deve procurar responder as seguintes questões: O que... porque ... e como avaliar?

Neste contexto, os objetos da avaliação (o que avaliar) seriam as geoformas, sendo a dimensão destas consideradas como um fator importante e que se divide em função da sua complexidade, ou seja, se constituem como geoformas isoladas, ou grupo de geoformas 
(PEREIRA et al. 2007, p.236). A figura 2 sintetiza a proposta destes autores para reconhecimento e classificação em função da dimensão e visualização de locais de interesse geomorfológico: geoformas isoladas seriam definidas por uma, ou um pequeno grupo de geoformas, e cuja escala de observação seria feita localmente; geoformas constituídas por um ou mais grupos só poderiam ser observadas em escala mais abrangente, exigindo movimentação dentro da própria área; e ainda, geoformas de grande dimensão que seriam observadas apenas em locais que permitem uma visão panorâmica.

Em resposta a questão do porque avaliar está relacionada a proteção e/ou divulgação de locais de interesse geomorfológico, subsidiando definição de geoformas vulneráveis e indicação de soluções em relatórios de Estudos de Impactos Ambientais (EIA), e mesmo de sua valorização como recurso natural aplicado ao turismo, e.g. (PEREIRA et al., 2007, p.236 e 237).

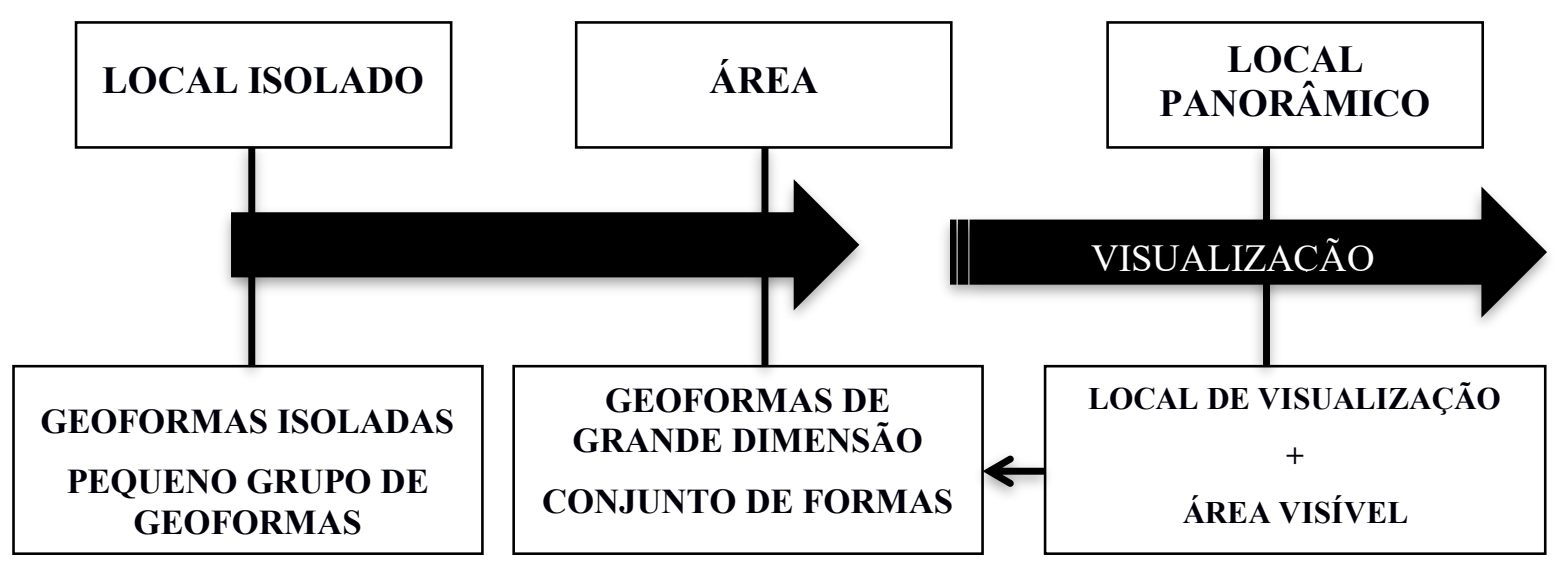

Figura 2. Classificação de locais de interesse geomorfológico, em função da dimensão e visualização (Modificado de: PEREIRA et al., 2007).

Como metodologia proposta para realização da avaliação do patrimônio geomorfológico estes autores propõem a aplicação de duas etapas de análise que são sequenciais e complementares e que são, também, detalhadas na tabela 1:

a) uma etapa de análise ligada a abordagem qualitativa, onde se busca a inventariação das geoformas, com finalidade principal de determinar quais delas podem ser consideradas “... como locais de interesse geomorfológico, independentemente da sua comparação, ou seriação numérica”. (ROCHA 2016, p.56);

b) uma abordagem quantitativa, que busca atribuir um caráter mais detalhado e preciso, utilizando-se de métodos numéricos na avaliação de critérios, permitindo a comparação entre localidades, ou o estabelecimento de uma seriação baseada no valor (ROCHA 2016, p.56), 
principalmente, se o objetivo do trabalho for à tomada de decisões relativas à conservação e/ou divulgação de locais de interesse geomorfológico.

Na sequência metodológica proposta por Pereira et al. (2007) na tabela 1 especifica os critérios utilizados em cada subetapa de avaliação para geoformas de qualquer dimensão espacial.

Tabela 1. Etapas e subetapas propostas para a inventariação e quantificação do patrimônio geomorfológico. Modificado de: Pereira et al. (2007).

\begin{tabular}{l|l}
\hline \multicolumn{1}{c|}{ Etapa } & \multicolumn{1}{c}{ Subetapas } \\
\hline \multirow{5}{*}{ Inventariação } & $\begin{array}{l}\text { a) } \text { identificação de potenciais locais de interesse geomorfológico: } \\
\text { locais identificados são listados, cartografados e georreferencia- } \\
\text { dos, atribuindo-se-lhes um código de identificação. }\end{array}$ \\
\hline b) avaliação qualitativa: através de uma ficha de avaliação que \\
busca considerer o valor local e avaliar a necessidade de proteção \\
e potencialidade de uso.
\end{tabular}

* A especificação dos valores atribuídos estão discriminados em Pereira et al. (2007; p.242 a 244).

Ressalta-se que o Valor Total (VT) de um local de interesse geomorfológico equivale a soma do valor geomorfológico (VGm) e do valor de gestão (VGt) - Tabela 2 - e o valor numérico final permite que seja realizada uma comparação entre os locais avaliados. E a etapa final desta proposta metodológica seria dada pelo somatório da posição ocupada para cada geoforma nos sete indicadores avaliados, e.g.: a geoforma "E" ocupa a 2a. posição no indicador VCi, a 3a. posição em VAd, a 2a. em VGm, a 2a. em VUs, a 1a. em VPr, a 2a. em VGt e a $2 \mathrm{a}$. em VT, somando-se $2+3+2+2+1+2+2=14$, que seria o valor correspondente no ranking final $(R k)$. Deste modo, os valores mais baixos obtidos em cada indicador avaliado (Vci, VAd, VGm, Vus, VPr, VGt, VT) leva a uma melhor posicionamento nos mesmos e 
indicará a melhor posição no somatório final $(R k)$. Este parâmetro determina, assim, o local com maior valor geomorfológico na área em avaliação e deve ser utilizado como suporte às decisões relativas a seleção dos locais de interesse geomorfológico para efeitos de divulgação (PEREIRA et al., 2007).

Nos valores hipotéticos exemplificados pela tabela 2 observa-se que o local B, apesar de ter sido pontuado com baixo VGm, é na verdade o local com Valor Total (VT) mais elevado, em face da pontuação obtida nos indicadores de gestão; enquanto o local C, apesar de possuir o VGm mais alto, classifica-se em $4^{\circ}$ lugar no indicador VT, devido aos baixos valores obstidos nos critérios de uso e preservacão.

Tabela 2. Seriação de locais hipotéticos para os sete indicadores avaliados e o Ranking Final (Rk). Fonte: Pereira et al. (2007).

\begin{tabular}{c|c|c|c|c|c|c|c|c}
\cline { 2 - 8 } & \multicolumn{1}{c}{ VCi } & VAd & VGm & VUs & VPr & VGt & VT & R \\
\hline $1^{\text {o. }}$ & $\mathbf{A}(4,83)$ & $\mathbf{C}(3,62)$ & $\mathbf{C}(7,37)$ & $\mathbf{B}(5,12)$ & $\mathbf{E}(2,75)$ & $\mathbf{B}(7,87)$ & $\mathbf{B}(14,07)$ & $\mathbf{E}(14)$ \\
\hline $2^{\text {o. }}$ & $\mathbf{E}(4,58)$ & $\mathbf{B}(2,62)$ & $\mathbf{E}(7,16)$ & $\mathbf{E}(4,07)$ & $\mathbf{B}(2,75)$ & $\mathbf{E}(6,82)$ & $\mathbf{E}(13,98)$ & $\mathbf{B}(15)$ \\
\hline $3^{\text {o. }}$ & $\mathbf{C}(3,75)$ & $\mathbf{E}(2,58)$ & $\mathbf{A}(6,71)$ & $\mathbf{A}(3,55)$ & $\mathbf{D}(2,50)$ & $\mathbf{A}(5,80)$ & $\mathbf{A}(12,51)$ & $\mathbf{A}(21)$ \\
\hline $4^{\text {o. }}$ & $\mathbf{B}(3,58)$ & $\mathbf{A}(1,88)$ & $\mathbf{B}(6,20)$ & $\mathbf{C}(3,27)$ & $\mathbf{A}(2,25)$ & $\mathbf{D}(5,61)$ & $\mathbf{C}(12,39)$ & $\mathbf{C}(23)$ \\
\hline $5^{\text {o. }}$ & $\mathbf{D}(2,94)$ & $\mathbf{D}(1,37)$ & $\mathbf{D}(4,31)$ & $\mathbf{D}(3,11)$ & $\mathbf{C}(1,75)$ & $\mathbf{C}(5,02)$ & $\mathbf{D}(9,92)$ & $\mathbf{D}(32)$ \\
\hline
\end{tabular}

A tabela de ranking final ( $R k$ ) (Tabela 2$)$ deve ser introduzida em um estudo desta natureza com o objetivo de minimizar a importância das pontuações absolutas (expressas no indicador VT), além de procurar valorizar o equilíbrio das pontuações obtidas nos sete indicadores considerados e indicar o local de maior valor geomorfológico (PEREIRA et al., 2007).

Nesta metodologia, podem-se distinguir claramente a inventariação e a quantificação como etapas da avaliação; no entanto, como mesmo os autores mencionam a avaliação integral exige que as etapas sejam realizadas em sequência, embora também seja possível realizá-las separadamente, de acordo com os objetivos pretendidos na análise de locais de interessse geomorfológico.

Procurando dar um fechamento a toda a discussão teórico-conceitual até este momento realizada, inserimos no debate o conceito de "geomorfossítio". Este pode ser traduzido como correspondendo a formas de relevo simples, ou de grande abrangência, nas quais é atribuído valor, a partir dos aspectos já destacados anteriormente, como necessários para uma classificacão de interesse geomorfológico, calcados em base científica. Ressaltamos, no entanto, que a visibilidade do geomorfossítio é variada, de acordo com a percepção do ser humano que, por sua vez, será diferenciada de acordo com o nível cultural educacional 
(PANIZZA 2001). Por isso, devemos procurar mostrar o que de singular existe em cada localidade, de forma clara e concisa, pois estes locais podem ser modificados, danificados ou, até mesmo, destruídos pela atividade humana; sendo seu valor geralmente desconhecido pelo público em geral e por profissionais de outras áreas científicas, que não das geociências, que existe a necessidade de aprofundar o conhecimento sobre o geomorfossítio, de modo a avaliar o seu valor científico, cultural e histórico (REYNARD e PANIZZA, 2005).

Para Gauchon (2012), qualquer patrimônio, assim como o próprio geomorfossítio, é resultado de uma construção cultural, ou seja, existe porque foi reconhecido e a sociedade o valorizou como tal, assumindo ser um recurso que merece consideração especial. Esta identificação e processos de reconhecimento, por meio de uma consciência coletiva, é o que é chamado de "patrimônio", e neste caso, de patrimônio geomorfológico.

Ressalta-se que em 2001, no âmbito da Associação Internacional de Geomorfólogos (IAG), foi criado um grupo de trabalho dedicado à temática do patrimônio geomorfológico, denominado Geomorphosites Working Group na $5^{\text {a }}$ Conferência Internacional de Geomorfologia, realizada em Tóquio. O trabalho deste grupo, como apontado por Reynard e Panizza (2005), é focado em quatro níveis de reflexão: a) definição/delimitação de geomorfossítios; b) métodos de avaliação; c) métodos de mapeamento e d) proteção.

Reynard e Panizza (2005) apontam que a principal lição aprendida, a partir da aplicação de métodos de avaliação, é a necessidade de desenvolver critérios mais claros e transparentes para descrever e medir os vários componentes de um geomorfossítio, possibilitando, desta forma, sua plena proteção. Desde a criação deste Grupo de Trabalho, conferências, publicações e mesmo realizações de cursos regulares, ou especiais (cursos de verão, intensivos, entre outros) se multiplicaram e são organizados por diversas universidades (REYNARD e CORATZA, 2007).

Hoje, o geopatrimônio, tanto geológico quanto geomorfológico, não é considerado apenas para fins de proteção, mas também pelo seu potencial de recuperação no desenvolvimento territorial sustentável, como apoio às atividades de geoturismo e de educação ambiental, como aponta CAYLA et al. (2012). Peyrache-Gadeau (2010) e Giusti (2012) destacam o geopatrimônio como tendo um papel importante no desenvolvimento de tais atividades, alcançando a condição de recurso territorial.

Podemos sintetizar que na análise e definição de localidades como patrimônio geomorfológico, de um dado lugar, podemos inserir o termo "geomorfossítio", definindo-o como paisagens de grande beleza cênica, que designam um conjunto de formas de relevo, e/ou depósitos correlativos de grande valor para a sociedade, principalmente no que se refere 
ao seu valor científico (PEREIRA, 2006). Deste modo, "o ambiente [environment] tende a ser visto como uma dimensão da existência humana" (THWAITES e SIMKINS, 2007, p.27).

Os conceitos de geoforma e geomorfossítio demonstram ser pertinentes para à construção da análise geográfica, haja vista que possuem uma relação intrínseca com conceitos geográficos chave como lugar e paisagem.

\section{Conclusões}

Esperamos que a discussão aqui apresentada contribua para elucidar algumas questões a respeito do emprego de conceitos geográficos relevantes na análise espacial, principalmente, aqueles que dão embasamento ao emprego dos termos "geoforma", entendida como "toda $e$ qualquer forma da superfície terrestre, resultante de processos geológico-geomorfológicos" (Manoso et al. 2010; p.2), que quando dotada de valor, especialmente científico, torna-se um "geomorfossítio", justificando e possibilitando sua preservação, conservação e divulgação, tanto no meio acadêmico, quanto na sociedade como um todo.

Acreditamos que a leitura e compreensão da organização da paisagem requer uma análise cuidadosa e que deve estar atrelada a bases conceituais sólidas para que possa contribuir de forma positiva para uma adequada utilização dos recursos naturais, de forma a maximizar os benefícios e minimizar os aspectos vinculados à degradação sociocultural e ambiental.

Deste modo, neste artigo procurou-se exemplificar o emprego de uma metodologia que procure valorizar o patrimônio geomorfológico de uma dada área, sendo este possível de apreensão em distintos níveis escalares de ocorrência, desde pelo reconhecimento e definição de geoforma e geomorfossítio em escala local até a escala regional. E, assim, procuramos demonstrar que existe uma flexibilidade para o emprego e definição escalar desta terminologia, desde que tal análise seja realizada com base na investigação científica de distintos aspectos que compõem a paisagem de um dado lugar.

Deste modo, sugerimos que o emprego desta abordagem de análise espacial seja, portanto, uma das formas mais sensíveis de se propor o uso adequado dos recursos naturais e socioculturais de um dado lugar, pois por meio deste serão ressaltados aspectos que levam à conservação e valorização da área de análise, além de procurar alertar a sociedade para o interesse e importância de recursos naturais abióticos, em particular os geológicos e geomorfológicos. 


\section{Referências Bibliográficas}

BRILHA, J. B. R. Património Geológico e Geoconservação: A Conservação da Natureza na sua vertente Geológica. Braga, Portugal: Palimage Editores. 190 p., 2005.

BRILHA, J.B.R. Inventory and Quantitative Assessment of Geosites and Geodiversity Sites: a Review. Geoheritage, p. 119-134, 2016.

CAUQUELIN, A. A invenção da paisagem. São Paulo: Martins Fontes. 2007.

CAVALCANTI, M. B. O lugar no mundo e o mundo no lugar: a Geografia da sociedade globalizada. Revista Caminhos de Geografia, Uberlândia, MG. v. 12, n. 40, p. 91-95, dez. 2011.

CAYLA, N.; HOBLEA, F.; BIOT, V.; DELAMETTE, M.; GUYOMARD, A. De l'invisibilité des géomorphosites à la révélation géopatrimoniale. Géocarrefour, Association des amis de la revue de géographie de Lyon, Lyon. v. 87, n.3-4, (mai.2013), p.171-186, 2012. Disponível em: http://geocarrefour.revues.org/8817. Acesso em: 4.fev.2017.

CORREAA, R. L.; ROZENDAHL, Z. Apresentando leituras sobre paisagem, tempo e cultura. In: CORREAA, R. L.; ROZENDAHL, Z. (Orgs.). Paisagem, Tempo e Cultura. Rio de Janeiro: Eduerj, 1998. p.7-11.

COSTA, F. R.; ROCHA, M. M. Geografia: conceitos e paradigmas - apontamentos preliminares. Revista GEOMOE, Campo Mourão, PR. v.1, n. 2, p.25-56, jun./dez. 2010.

CRESSWELL, T. Place. A short introduction. Malden: Blackwell, 2010

CUNHA, L.; VIEIRA, A. Património geomorfológico, recurso para desenvolvimento local em espaços de montanha. Exemplos no Portugal Central. In: Cadernos de Geografia $-3^{a}$. Série. Coimbra: Faculdade de Letras/Universidade de Coimbra. n. 21/23 - 2002/04, p.15-28, 2004. Disponível em: https://www.uc.pt/fluc/depgeotur/publicacoes/Cadernos_Geografia/ Numeros_publicados/CadGeo21_23/artigo02. Acesso em: 11.jan.2017

FIGUEIRÓ, A.S.; VIEIRA, A.A. B.; CUNHA. L. Patrimônio geomorfológico e paisagem como base para o geoturismo e o desenvolvimento local sustentável. CLIMEP - Climatologia e Estudos da Paisagem, Rio Claro (SP). v.8, n.1, janeiro/junho, p. 49-81. 2013. Disponível em: http://www.periodicos.rc.biblioteca.unesp.br/index.php/ climatologia/index. Acesso em: 11.jan. 2017

GAUCHON, C. Un géomorphosite qui sème la discorde: les arches naturelles de la Grande Chartreuse (Isère, France). Géocarrefour, Association des amis de la revue de géographie de Lyon: Lyon. v. 87, n. 3-4, (mai.2013). 2012. p.249-259. Disponível em: https://hal.archivesouvertes.fr/halsde-00823181. Acessado em: 3.fev.2017.

GIUSTI, C. Les sites d'intérêt géomorphologique: un patrimoine invisible? Géocarrefour, Association des amis de la revue de géographie de Lyon: Lyon. v. 87, n. 3-4, (mai.2013), p. 151-156, 2012. Disponível em: http://geocarrefour.revues.org/8834. Acesso em: 04.fev.2017. 
GOMES, P. C. C. O Lugar do Olhar: elementos para uma geografia da visibilidade. Rio de Janeiro: Bertrand Brasil, 2013.

GOMES, P. C. C; RIBEIRO, L. P. A produção de imagens para a pesquisa em Geografia. Espaço e Cultura - UERJ, Rio de Janeiro, RJ. n. 33, p.27-42, jan./jun. 2013.

HAESBAERT, R.; NUNES PEREIRA, S.; RIBEIRO, G. (Orgs.). Vidal, Vidais. Textos de geografia humana, regional e política. Rio de Janeiro: Bertrand Brasil, 2012.

HARTSHORNE, R. The Nature of Geography: A Critical Survey of Current Thought in the Light of the Past. Annals of the Association of American Geographers, Washington. v. 29, n. 3 e 4, p.173-658, sep.1939.

HUBBARD, P. Space/Place. In: ATKINSON, D.; JACKSON, P.; SIBLEY, D.; WASHBOURNE, N. (Eds.). Cultural geography. A critical dictionary of key concepts. Londres: I.B. Tauris, 2005. p.41-48.

JAKOB, M. Le paysage. Genebra: Infolio. 2008.

MANOSO, F. C.; COUTO, E. V.; FORTES, E.; NÓBREGA, M. T. Geoformas no município de Faxinal, Paraná, Brasil: origem e potencial turístico. In: SEMINÁRIO LATINO AMERICANO DE GEOGRAFA FÍSICA, 6.; SEMINÁRIO IBERO AMERICANO DE GEOGRAFIA FÍSICA, 2., 2010, Coimbra, Portugal. Anais... Coimbra: Departamento de Geografia, Universidade de Coimbra, Porto e Minho, 2010. 15p. Disponível em: <http://www.uc.pt/fluc/cegot/VISLAGF/actas/tema5/fernando>. Acesso em: 23 jan. 2017.

NOGUÉ, J. Entre paisajes. Barcelona: Àmbit. 2009.

OSLENDER, U. Fleshing out the geographies of social movements: Colombia's Pacific coast black communities and the "aquatic space". Political Geography, Amsterdam. v. 23, n. 8, p.957-985, nov. 2004.

PANIZZA, M. Geomorphosites: concepts, methods and examples of geomorphological survey. Chinese Science Bulletin, v. 46 (Suppl.1), p. 4-5, jan./dec. 2001.

PELFINI, M.; BOLLATI, I. Landforms and geomorphosites ongoing changes: Concepts and implications for geoheritage promotion. Quaestiones Geographicae, Poznań. v. 33, n. 1, p.131-143, mar. 2014. Disponível em: http://geoinfo.amu.edu.pl/qg/archives/2014/ QG331_131-143.pdf. Acesso em: 29 de abr. 2017.

PEREIRA, A. R. Património geomorfológico no litoral sudoeste de Portugal. Finisterrra Revista Portuguesa de Geografia, Lisboa. v. 30, n. 59-60, p.7-25, dez. 1995. Disponível em: http://revistas.rcaap.pt/finisterra/article/view/1813/1499. Acesso em: 28 jan.2017.

PEREIRA, P. J. S. Patrimônio geomorfológico: conceptualização, avaliação e divulgação. Aplicação ao Parque Natural de Montesinho. 2006. 395 f. Tese (Doutorado em Ciências) Escola de Ciências, Universidade do Minho, Minho, Portugal, 2006. Disponível em: http://repositorium.sdum.uminho.pt/handle/1822/6736. Acesso em: 29 jan.2017.

PEREIRA, P. J. S.; PEREIRA, D.; ALVES, M. I. C. Patrimônio Geomorfológico: da actualidade internacional do tema ao caso português. In: CONGRESSO DE GEOGRAFIA 
PORTUGUESA, 5., 2004, Guimarães, Portugal. Actas... Guimarães: Associação Portuguesa de Geógrafos, 2004, 18p. Disponível em: https://www.researchgate.net/profile/Paulo_Pereira34/publication/283224513_Patrimonio_ge omorfologico_da_actualidade_internacional_do_tema_ao_caso_portugues/links/562e99be08a ef25a24444e7b/Patrimonio-geomorfologico-da-actualidade-internacional-do-tema-ao-casoportugues.pdf?origin= publication_list\&ev=prf_pub_xdl. Acesso em: 28 jan.2017.

PEREIRA, P. J. S.; PEREIRA, D. I.; ALVES, M. I. C. Avaliação do Património Geomorfológico: proposta de metodologia. Publicações da Associação Portuguesa de Geomorfológos, Guimarães - Porto, Portugal. v.5, p.235-247, dez. 2007. Disponível em: https://repositorium.sdum.uminho.pt/bitstream/1822/7406/1/PereiraP_etal.pdf Acesso em: 28 jan.2017.

PEREIRA, D.; PEREIRA, P. J. S.; ALVES, M. I. C.; BRILHA, J. B. R. Inventariação temática do patrimônio geomorfológico português. Publicações da Associação Portuguesa de Geomorfológos, Guimarães - Porto, Portugal. v.3, p.155-159, dez. 2006. Disponível em: https://repositorium.sdum.uminho.pt/bitstream/1822/5370/1/ geomorf.pdf. Acesso em: 27 jan.2017.

PEYRACHE-GADEAU, V. Renouvellement des ressources et diversité des durabilités territoriales. In: MAILLEFERT, M.; PETIT, O.; ROUSSEAU, S. La problématique du développement durable vingt ans après: nouvelles lectures théoriques, innovations méthodologiques et domaines d'extension. Lille, France: P.I.E Peter Lang. p.237-254, 2010.

REYNARD, E.; CORATZA, P.; REGOLINI-BISSIG, G. (eds.). Geomorphosites. München: Verlag Dr. Friedrich Pfeil, 2009.

REYNARD, E.; CORATZA, P. Geomorphosites and geodiversity: a new domain of research. Geographica Helvetica, Zurique. v. 62, n. 3, p. 138-139, sep. 2007. Disponível em: http://www.geogr-helv.net/62/138/2007/. Acessado em: 6 fev.2017.

REYNARD, E.; PANIZZA, M. Géomorphosites: definition, evaluation et cartographie. Une introduction. Géomorphologie - Relief, Processus, Environnement, Paris. v. 11, n. 3, p.177180, sep. 2005. Disponível em: https://geomorphologie.revues.org/336\#text. Acesso em: 30 jan.2017.

ROCHA, H. S. Geoformas e potencial geoturístico de Santiago, Cabo Verde - África. 2016. 100 f. Trabalho de Conclusão de Curso (Graduação em Geografia) - Depto. Centro de Ciências/UFCE, Fortaleza. 2016.

RODRIGUES, J.; NETO de CARVALHO, C.; OLIVEIRA, T. Patrimônio Geomorfológico de Monsanto. Publicações da Associação Portuguesa de Geomorfológos, Guimarães - Porto, Portugal. v.6, p. 243-248, dez. 2009. Disponível em: http://www.naturtejo.com/ficheiros/ conteudos/files/Trabalho\%2064.pdf. Acesso em: 30 jan.2017.

SANTOS, M. A Natureza do Espaço: Técnica e Tempo. Razão e Emoção. São Paulo: Hucitec, 1996.

SOUZA, M.L. Lugar e (re[s])significação especial. In: SOUZA, M.L. Os Conceitos fundamentais da pesquisa sócio-espacial. Rio de Janeiro: Bertrand Brasil. 2013. p.111-134. 
THWAITES, K.; SIMKINS, I. Experiential Landscape: an approach to people, place and space. Nova York: Routledge. 2007.

TUAN, Yi-Fu. Espaço e lugar. A perspectiva da experiência. São Paulo: Difel, 1983.

TUAN, Yi-Fu. Segmented worlds and self. A study of group life and individual consciousness. Minneapolis: University of Minnesota Press, 1984.

TUAN, Yi Fu. Cosmos y hogar.Un punto de vista cosmopolita. Barcelona: Melusina. 2005.

VERDUM, R.; MAZZINI, L. F. Temáticas rurais: do local ao regional. Porto Alegre: Editora da UFRGS, 2009.

VIEIRA, A; CUNHA, L. Património geomorfológico - tentativa de sistematização. In: SEMINÁRIO LATINO-AMERICANO DE GEOGRAFIA FÍSICA, 3., 2004, Puerto Vallarta, México. Actas... Puerto Vallarta: Instituto de Geografia, México, CD-Rom, 14p. 2004. Disponível em: https://repositorium.sdum.uminho.pt/bitstream/ 1822/35546/1/VieiraCunhaPatrimonioGeomorf.pdf. Acesso em: 27 jan. 2017. 